\title{
Mother-TO-ChILD TRANSMISSION OF HIV IN CANADA: A Population Health Risk Management Perspective
}

\author{
Gail Webber, MD, CCFP, MA
}

Associate Staff, Department of Family Practice, Division of Maternal and Newborn Care

General Campus, The Ottawa Hospital, Ottawa ON

Abstract: The standard of prenatal care in Canada for preventing transmission of the human immunodeficiency virus (HIV) from mother to infant is universal counselling and voluntary testing of pregnant women for the virus. Appropriate treatment of HIV-positive women reduces the risk of viral transmission to the infant to less than $1 \%$. Despite this, too many children in Canada are born with HIV because their mothers were not tested. The barriers to screening include lack of appropriate resources and lack of training in this area. As a result, physicians find HIV test-counselling too time-consuming or believe that testing is not relevant to their patient population. Risk management strategies to improve screening rates and decrease transmission, including community action and technological strategies such as vaccines and rapid testing kits, are reviewed. The "advisory" option, the process of risk communication between health-care providers, the government, and the public, for the purpose of making recommendations, is a key component toward the success of universal screening. A shift to simplified screening and "opt-out" testing procedures is recommended.

Résumé : Au Canada, le counseling systématique des femmes enceintes et le dépistage volontaire du virus constituent la norme de soins prénatals pour la prévention de la transmission du virus de l'immunodéficience humaine $(\mathrm{VIH})$ de la mère à l'enfant. Le traitement adéquat des femmes infectées par le $\mathrm{VIH}$ réduit le risque de transmission virale à l'enfant à moins de I \%. Malgré ce fait, au Canada, trop d'enfants naissent infectés par le VIH parce que celui-ci n'a pas été dépisté chez leur mère. L'absence de dépistage peut s'expliquer par deux obstacles : le manque de ressources et le manque de formation dans ce domaine. Pour ces raisons, les médecins trouvent souvent que le dépistage et le counseling prennent trop de temps ou que ces mesures ne sont pas justifiées, à cause du type de patientes qu'ils traitent. Parmi les stratégies de gestion du risque à adopter pour améliorer les taux de dépistage et réduire les taux de transmission, nous examinons l'action communautaire et des approches technologiques comme les vaccins et les trousses de tests rapides. L'option « consultative " (qui consiste à assurer un processus de communication

\section{Key Words}

Vertical transmission, HIV, screening, risk management

Competing interests: None declared.

Received on December 10, 2002

Revised and accepted on March 21, 2003 sur les risques entre les fournisseurs de soins, les gouvernements et le public, dans le but de faire des recommandations) est un élément essentiel des efforts visant à assurer un dépistage universel. Nous recommandons de mettre en place une méthode de dépistage simplifiée et des modalités prévoyant des possibilités " d'exemption 》 du test.

J Obstet Gynaecol Can 2003;25(9):751-9.

\section{THE HUMAN IMMUNODEFICIENCY VIRUS IN CANADA}

Although the heaviest impact of the human immunodeficiency virus (HIV) and acquired immune deficiency syndrome (AIDS) has been on the developing world, HIV/AIDS continues to be an important health concern in industrialized countries. In Cana$\mathrm{da}$, the initial prevalence of HIV/AIDS centred on men who had sex with men; injection-drug users were another high-risk population. The virus is now well-established in the heterosexual population. A 2001 Health Canada report ${ }^{1}$ stated that women represented $25 \%$ of HIV-positive persons in Canada, and the percentage continues to grow. As most of these HIV-positive women are of child-bearing age, the risk of passing the virus to their offspring is of particular concern. The majority of HIV-positive women in Canada (63.5\% in 2001) became infected through heterosexual contact; a smaller percentage became infected through injection-drug use or blood transfusions. ${ }^{1}$ The estimated rate of HIV infection among pregnant women in Canada is 3 to 4 per 10000 pregnant population, with a higher proportion in large urban regions such as Vancouver and Montreal. ${ }^{1}$

Mother-to-child transmission (MTCT) of HIV has been a concern from the beginning of the AIDS epidemic. In North America, an HIV-positive woman without treatment faces a $25 \%$ risk of passing the virus to her newborn. ${ }^{2}$ A recent multicentre international trial ${ }^{3}$ demonstrated that treatment of the mother with a combination of antiretrovirals reduced MTCT rates to $1 \%$. The success of treatment is, of course, dependent on identifying the mother as HIV-positive before she gives birth. Reducing MTCT requires screening of all pregnant women and offering counselling and treatment to those who are HIV-positive. Remis et al. ${ }^{4}$ estimated that in Ontario 40 women with undiagnosed HIV conceive each year, resulting in a prevalence of 1 in 3500 pregnant population. This prevalence is higher than 
congenital hypothyroidism ( 1 in 4000) or phenylketonuria ( 1 in $15000), 2$ conditions for which infants are universally screened. ${ }^{4}$

\section{SCREENING: GUIDELINES AND REALITY}

In 1995, the Canadian Medical Association (CMA) published Counselling Guidelines for HIV Testing, ${ }^{5}$ the most current recommendations for Canadian health-care providers. The 1995 guidelines emphasize extensive patient education about risky behaviours that increase the probability of transmission of HIV, and provide a checklist for physicians on items to discuss with women both prior to (pretest) and after (post-test) screening for HIV (Table 1). The pretest counselling includes an exploration into the woman's risk of contracting the virus, and education about reducing risk, testing options, and the potential benefits and harms of being tested. The woman is then asked to return for post-test

TABLE I

\section{HIV COUNSELLING CHECKLIST FOR PHYSICIANS}

\section{Pretest Counselling}

A person's request for HIV testing should be honoured.

- Explore risk history and discuss reasons for the test.

- Assess the person's risk of having been exposed to or of being infected with HIV.

- Provide information about HIV infection and testing, including the meaning of positive, negative, and indeterminate test results, and the impact of the window period.

- Discuss risk reduction and explore specific ways in which the person can avoid or reduce risk-producing behaviour.

- Identify testing options available in the region, specifically nominal, non-nominal, and anonymous testing.

- Discuss the potential benefits and harms of being tested and of being found HIV-positive.

- Discuss the confidentiality of test results in relation to office or clinical procedures, communicating results to other health-care officials, provincial reporting requirements, and partner notification.

- Discuss the stress related to waiting for test results and possible reactions to learning the results.

- Assess the window period by identifying the most recent risk event, and plan an appropriate time for testing.

- Obtain and record informed consent, whether provided in writing or verbally, before testing is conducted.

- Arrange a return appointment, after a predetermined interval, for a face-to-face visit to inform the patient of the test results.

A person has the right to decline testing.

\section{Post-test Counselling}

HIV test results are given only in person.

- Assess the patient's understanding of the test results.

- Encourage the patient to express feelings and reactions.

Negative and indeterminate result

- Discuss any need for repeat testing.

- Review the ways in which HIV is transmitted.

- Review risk-producing behaviour and assess the patient's commitment to risk-reducing strategies.

Positive result

- Assess the psychological response to being HIV-positive.

- Plan how the patient can overcome adverse psychological reactions to being found HIV-positive.

- Arrange additional psychological and social support services as needed.

- Provide reassurance about the person's immediate safety.

- Arrange for medical follow-up.

- If possible, review transmission modes and risk-reduction strategies.

- Arrange for partner notification, if necessary.

Other important issues (emphasize early if poor follow-up is likely)

- Discuss health, reproductive, and treatment issues.

- Review importance of partner testing and notification, and offer assistance if the person needs it.

- Reiterate the patient's right to privacy and confidentiality with respect to medical information.

Adapted from Counselling Guidelines for HIV Testing, ${ }^{5}$ and reprinted by permission of the publisher, Canadian Medical Association. 
counselling, which covers issues based on the test results. Riskreduction strategies are emphasized regardless of whether the test result is positive, negative, or indeterminate, and support to a woman who tested positive for HIV is seen as a priority. The guidelines also specifically recommend that HIV testing be discussed with pregnant women over several visits (Table 2).

The CMA guidelines are considered to be the standard of care in Canada: it is expected that any offer of HIV testing should be accompanied by the appropriate pre- and post-test counselling. The guidelines are comprehensive, and implementing them requires a significant time commitment.

The recommendation for universal counselling of pregnant women regarding HIV/AIDS has also been put forward by the Society of Obstetricians and Gynaecologists of Canada (SOGC), ${ }^{6}$ the Canadian Paediatric Society (CPS), ${ }^{7}$ and the Canadian College of Family Physicians (CCFP). ${ }^{8}$ Despite the available evidence and strong encouragement from professional organizations to physicians to counsel all pregnant women in Canada regarding screening for HIV, counselling and screening are not always performed.

A study' in Chicago found that 65 out of 81 HIV-positive women $(80 \%)$ had at least 1 missed opportunity for diagnosis in the previous 12 months, during which they had seen a health-care provider but not been offered testing. Of particular concern was that of 25 women who were pregnant, 12 had failed to be identified as HIV-positive during their pregnancy. ${ }^{\text {? }}$ In Canada, Gruslin et al. ${ }^{10}$ compared the HIV screening rates from February to April 1996 and from February to April 1998 at the General Campus of The Ottawa Hospital, after a departmental policy and specific educational initiatives to increase screening had been implemented in June 1997. The rate of screening increased from $13 \%$, prior to the initiative, to $72 \%$, after the initiative. The authors reported that $78 \%$ of the women not tested in 1998 had been urgent transfers to the hospital and so had missed the clinic opportunity of counselling and voluntary testing. Thus, $28 \%$ in total were not tested, including $6 \%$ of the group who had had the opportunity to be tested at The Ottawa Hospital.

Pediatricians at the Hospital for Sick Children, in Toronto, reported 6 cases of MTCT-acquired HIV from August 1999 to July 2001. In all 6 cases, the mother was unaware that she had $\mathrm{HIV}$, and had not been screened during pregnancy. ${ }^{11}$ On closer questioning, it was found that 2 of the women had been offered the test but deferred it, and later assumed that the test had been completed with routine prenatal blood work. A third had been offered the test and accepted, but testing was not done. The other 3 women had not been offered the test. The authors of the paper stated: "Our results suggest that incomplete application of universal prenatal HIV counselling and voluntary testing guidelines by health-care providers is largely responsible for the continued occurrence of perinatal transmission of HIV in Ontario." 11

\section{BARRIERS TO UNIVERSAL SCREENING OF PREGNANT WOMEN FOR HIV IN CANADA}

During the fall of 1997 and the winter of 1998 , a national survey of Canadian physicians was conducted to study physicians' practices and attitudes toward prenatal HIV screening, as well as physicians' perceptions of the barriers to the provision of universal

\section{TABLE 2}

\section{PRENATAL TESTING PROCEDURES}

We recommend offering HIV testing and counselling to all pregnant women. However, the procedure should differ from that used for other prenatal tests, and should be carried out over several prenatal visits.

At the first prenatal visit

- Follow the standard practice of exploring desirability of pregnancy, presence of social support, living situation, and stability of relationship. $\times$

- Discuss advantages and disadvantages of testing for HIV for both mother and child and discuss the availability of treatment to reduce the chance of transmission to the fetus.

- Provide information on mother-to-child transmission.

- Discuss strategies to reduce the risk of acquiring HIV and other STDs during pregnancy. Provide written material along with information about local resources.

- Provide a separate requisition for the HIV test, so that the woman may decide against HIV testing without jeopardizing other prenatal screening.

\section{On subsequent visits}

- If the woman has chosen not to be tested, explore and record the reason.

- If the woman has not yet decided, re-explore the advantages and disadvantages of testing during pregnancy.

- If the woman has chosen to be tested, obtain and record receipt of informed consent.

Adapted from Counselling Guidelines for HIV Testing, ${ }^{5}$ and reprinted by permission of the publisher, Canadian Medical Association. 
screening. ${ }^{12}$ Other issues addressed by the study were training and education, and access to referral sources. Thirty percent of physicians were found to be offering testing only to those women perceived as being at high risk. When questioned specifically about barriers, $80 \%$ of family physicians and $90 \%$ of obstetricians from across Canada stated that they felt the remuneration for counselling regarding HIV screening to be inadequate; nevertheless, most offered screening. The authors summarized that physicians were more likely to screen women for HIV if they did not think it was too time-consuming, if they did not think the prevalence rate was too low to justify universal screening, and if they felt that they had adequate training and referral sources.

Remis et al. ${ }^{4}$ found that among 5 Canadian provinces for which information on HIV testing in pregnancy was available (representing $90 \%$ of the pregnancies in Canada) the weighted average of screening rates was $70 \%$, ranging from $55 \%$ in Ontario to $96 \%$ in Alberta. ${ }^{4}$ The authors suggested 5 reasons why physicians may not offer the test: a lack of understanding of the significance of testing; the benefits are seen as small in a low-risk serting; the potential risks of testing are perceived as high; the current recommendations for pretest counselling are too time-consuming; and a discussion of issues around HIV, such as sexuality and injection-drug use, makes both patients and physicians uncomfortable. In addition, the authors suggest that some women may be refusing the test: high-risk women may be afraid of the results, and low-risk women may not see the test as worthwhile; some women may fear their partner's response or may not be able to consent to testing without their partner's permission; women of immigrant status may avoid testing for fear of deportation should they be detected as being HIV-positive. ${ }^{4} \mathrm{~A}$ study of MexicanAmerican women found similar reasons for declining HIV screening in pregnancy. ${ }^{13}$

Remis et $a l^{4}{ }^{4}$ also point to failure to collect the specimen, which was responsible for several HIV transmissions in Ontario, and to improperly completed screening requisitions as further factors involved in reasons for MTCT of HIV. Women who come to Canada as visitors or immigrants from high-prevalence countries and have no prenatal care after their arrival may also escape screening.

\section{RISK MANAGEMENT STRATEGIES}

Risk, as defined by Dr Daniel Krewski in his lecture, "Population Health Risk Assessment" (September 10, 2002), is the probability of a consequence or hazard occurring, with perception of the risk being an exponent of the consequence; that is,

$$
\text { Risk }=\text { Probability } \times \text { Consequence } \mathrm{Perception}^{\text {Pan }}
$$

Risk perception is a crucial factor in the risk equation of MTCT of HIV. In order to reduce MTCT of HIV, perceptions of both health-care providers and pregnant women have to be addressed. As discussed above, some physicians fail to offer universal screening because of concerns about insufficient time, remuneration, training, resources, or perceptions that their patient population is low-risk. Similarly, some women refuse testing because they think they are not at risk, or they fear the consequences of testing positive. Influencing these perceptions will require a multi-faceted approach.

Risk management strategies will be discussed through a consideration of regulatory, economic, advisory, community action, and technology options.

\section{REGULATORY OPTIONS}

Regulatory options in risk management include government stipulations or legal requirements, which require enforcement. In the area of HIV testing, 1 potential option for regulation is mandatory testing, such as occurs in the United States, where some states require HIV testing of all newborns. However, if a newborn tests positive, the mother must be positive, and therefore has lost her right to choose whether or not to be tested. Some feel that the loss of liberty in mandatory regulations is warranted in order to protect the health of infants. Most Canadians would disagree: ethically, it would be difficult to justify forced screening of mothers, given the implications of a diagnosis of HIV..$^{14}$ In addition, mandatory testing might drive some women away from any prenatal care at all, thereby compromising rather than protecting their health and the health of their infants. Voluntary testing programs can be highly successful when properly implemented. Legally, mandatory testing would not be acceptable under the Canadian Charter of Rights and Freedoms. ${ }^{15}$

A second regulatory possibility is self-regulation of the medical profession. The government would provide surveillance rates of MTCT of HIV, and the profession would take on the task of assessing why these children were born with HIV and how these infections could have been prevented. This process of self-regulation could be organized by national organizations such as the SOGC and the CPS. The purpose of self-regulation would not be to discipline providers who fail to screen, but rather to improve the system, such that all women are given the opportunity to be screened and treated. Knowing that the profession has a process of self-regulation may serve to motivate practitioners who are not yet universally screening the pregnant women in their practices.

\section{ECONOMIC OPTIONS}

Traditional economic options to manage risk that could be applied to reducing the MTCT of HIV include compensatory measures to those who suffer from the disease, incentives to improve counselling, and fiscal support.

In Canada, health care for women and children with HIV is fully covered by provincial health plans, but there are other costs associated with having an infant with HIV, in particular, breast milk substitutes. Presently, a woman in Ontario can obtain free 
formula for the first year of her infant's life. Other compensatory funds should be available for women with HIV, to cover such costs as travel to doctors' appointments, childcare, and nursing support when isolation from the general community is necessary.

Incentives to improve counselling may be awarded to provinces, hospitals, or individual practitioners. The resources gained by this method may be reinvested into the health-care system.

Fiscal support of HIV testing could be used in numerous ways. One of the barriers to universal screening that physicians identified was the lack of resources available to them. Services such as the Motherisk HIV Healthline, which provides information to patients and physicians across Canada, are useful resources. ${ }^{16}$ Similarly, continuing medical education events and focus groups would be helpful to educate physicians and the public about universal testing. Remuneration for HIV counselling should be considered. Finally, research and evaluation of existing programs need to be priorities.

\section{ADVISORY OPTIONS}

A useful strategy for the success of universal screening is the "advisory" option. This can be summarized as the process of risk communication between the different parties or stakeholders, specifically health-care providers, the government, and the public, for the purpose of making recommendations. As indicated in the Communications Processes Model ${ }^{17}$ (Figure 1), communication of risk occurs between and within the expert sphere and the public sphere. Thus, health-care professionals share their expertise with each other and with their patients and the public. Similarly, governments have recommendations for physicians to follow, as well as advisories for the public. Risk communication flows in multiple directions.

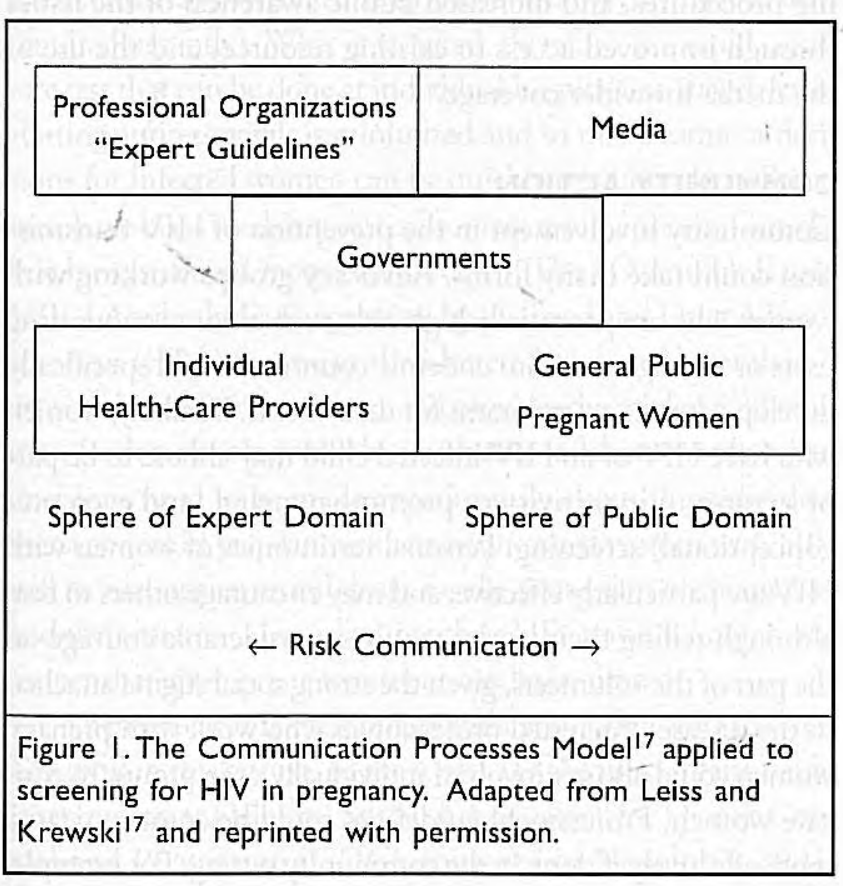

Expert opinion, as represented by guidelines produced by professional organizations, can play an important role in advisory options in this area. The 1995 CMA guidelines for screening HIV (Table 1), and their application to pregnant women (Table 2), are extremely thorough and comprehensive. For busy physicians, some of whom mentioned lack of time as one of the factors why they did not provide screening, implementing such guidelines can be daunting. Remis and Patrick ${ }^{18}$ have advocated for a simplification of the pre- and post-test counselling for pregnant women and an integration into the routine prenatal visit. Risk factors for HIV can be quickly determined. The woman is given the opportunity to refuse; however, there does not need to be a lengthy discussion unless she is uncomfortable or there are issues in her particular case that warrant specific counselling. Remis and Patrick comment, "Counselling a pregnant woman with regard to HIV infection clearly involves more than obtaining informed consent. It can also provide information and awareness that will help uninfected women remain so (after all, well over $99 \%$ of pregnant women are not infected). Although this type of counselling is important and potentially very effective, it can be done at any time during or after the patient's pregnancy and should not be confused with that provided for the purpose of prescribing a test that may save the life of her child." 18

A revision of the CMA guidelines for screening HIV is needed, particularly as they apply to pregnant women. Emphasis needs to be placed on maximizing the number of women screened in a timely manner over several visits, in order to prevent even 1 child developing HIV, rather than on lengthy discussions of risk in women who are at low risk. Recommendations from all professional organizations (SOGC, CPS, CCFP, and CMA) should encourage physicians to incorporate counselling toward HIV screening into routine prenatal care.

Government advisories to health-care providers should complement those of the professional organizations. Health Canada has promoted universal voluntary screening of pregnant women, ${ }^{19}$ but as health is a provincial responsibility in Canada, the implementation varies widely across the country. Yukon, British Columbia, Saskatchewan, Manitoba, Ontario, Quebec, New Brunswick, and Prince Edward Island formally recommend screening as an "opt-in" approach, in which women are required to specifically consent to HIV testing. Ontario's former provincial laboratory requisitions for prenatal testing illustrate this well. Prior to January 2002, the provincial laboratory would only perform HIV testing if 2 boxes on the form, indicating that counselling had been done and informed consent given, had been checked. In contrast to this method, Northwest Territories, Nunavut, Alberta, Nova Scotia, and Newfoundland and Labrador use an "opt-out" approach, where physicians are expected to routinely offer HIV testing as part of prenatal care. The woman is informed that she will be tested unless she specifically objects. There is no 
TABLE 3

NUMBER OF WOMEN DELIVERING AND PERCENTAGE RECEIVING PRENATAL HIV TESTING, BY TESTING APPROACH, YEAR, AND PROVINCE - CANADA, 1999-2001

\begin{tabular}{|llcr|}
\hline Province & Year & Testing Approach & No. (\%) of Liveborn \\
\hline Alberta & 2000 & Opt-out & $37963(98)$ \\
Newfoundland and Labrador & 2001 & Opt-out & $4770(94)$ \\
Quebec & 1999 & Opt-in & $73781(83)$ \\
British Columbia & 1999 & Opt-in & $41739(80)$ \\
Ontario & 2001 & Opt-in & $129758(54)$ \\
\hline Adapted from Centers for Disease Control and Prevention & & \\
\end{tabular}

requirement for formal counselling, but the test is still voluntary. Screening practices in Canada and the United States were examined by the Centers for Disease Control and Prevention, and in their report of November 15, 2002, the "opt-out" approach was clearly more effective, as illustrated by a comparison of 5 Canadian provinces (Table 3). ${ }^{20}$

In their study of pregnant women's experiences of HIV screening in pregnancy in Canada, Leonard et al. ${ }^{21}$ concluded that women felt strongly that they should be offered HIV testing as part of routine prenatal care, and be given the choice to "opt-out" rather than "opt-in." In an article on preventing MTCT of HIV, O'Connor and MacDonald 22 stated, "Let us all work to ensure that the only infants in Canada found to be HIV-positive fall into the very small group for whom prophylaxis failed. 'Opt-out' testing would ensure that it would never again be because their mothers were not offered the opportunity for screening and, therefore, did not receive treatment because they did not know about their seropositive status."

Walmsley has recommended the screening of fathers, or the repeat screening of mothers who continue high-risk behaviour during pregnancy; she reports, in 2 recent cases in Ontario, the pregnant woman acquired HIV after she had been screened, because she continued to have unprotected intercourse with her HIV-positive partner. ${ }^{23}$ Ongoing risks in either parent's behaviour may warrant repeat screening.

In addition to risk communication within the expert sphere, from professional organizations and governments to health-care providers, there are advisories made to the public from the experts and government. Both the SOGC and the CPS have patient information on their Web sites promoting HIV testing during pregnancy. The government of Ontario has also produced a Health Facts Web site describing the prenatal HIV testing program. The AIDS Clearinghouse of the Canadian Public Health Association produces "Important News for Pregnant Women," a pamphlet available in English, French, Chinese, Somali, Spanish, Inuktitut, and Swampy Cree. ${ }^{24}$

There are also numerous provincial AIDS hotlines, and the Motherisk's HIV Healthline, based at the Hospital for Sick Children in Toronto, provides information, specifically about
HIV in pregnancy, ${ }^{16}$ to patients and health-care providers across Canada. While all these materials and services are helpful, women who need the information may not be aware of these resources or may not have the time or the ability to access the Internet. Hotlines have a useful function, but people must be motivated to seek them out. The multilingual pamphlets are certainly a good attempt at improving the accessibility of the information; distribution to health-care providers' offices would ensure their wider readership, and aid busy physicians in communicating important information effectively.

International events such as World AIDS Day could provide opportunities to focus on MTCT and its prevention. Newspapers, radio, and television programming would be effective media for risk communication. Videos would be helpful for reaching populations who lack literacy skills.

In summary, the advisory option of risk management includes an array of strategies to maximize the number of women screened during pregnancy: modified professional guidelines (to simplify and facilitate screening), "opt-out" testing procedures, and increased public awareness of the issues through improved access to existing resources and the use of the media for wider coverage.

\section{COMMUNITY ACTION}

Community involvement in the prevention of HIV transmission could take many forms. Advocacy groups working with women who are potentially high-risk, such as intravenous drug users or immigrants from endemic countries, could specifically develop educational programs for their clients. Similarly, women who have HIV or an HIV-infected child may choose to be part of a community activity to promote prenatal (and even preconceptional) screening. Personal testimonies of women with HIV are particularly effective, and may encourage others to test, although telling their stories requires considerable courage on the part of the volunteers, given the strong social stigma attached to the disease. Interested professionals who work with prenatal women could also get involved individually or in groups to educate women. Professional guidelines could be communicated more effectively if done in the community setting. For example, 
HIV screening should be routinely addressed at early prenatal classes, and couples should be encouraged to seek testing if they have not already been offered it. There is much potential for increased screening rates if the discourse reaches the community level; all stakeholders should consider how they may play a role in community action for this cause.

\section{TECHNOLOGY}

There are 2 techological options for risk management, 1 of which (vaccines) would abolish the need for routine prenatal screening for HIV altogether. Much research has gone into the development of a vaccine against AIDS, but most of the vaccines developed are years away from clinical use. Canada is participating in Phase III trials (i.e., involving humans) of the AIDSVAX vaccine, which is active against subtype $B$, the strain of HIV found mostly in the developed world. ${ }^{25}$ Unfortunately, early results of this trial, involving Canada, the Netherlands, and the United States, have been disappointing.

Clearly, an effective vaccine could have a huge impact on public health. Although still a remote possibility for now, it is foreseeable that HIV may some day be managed as hepatitis B currently is, by vaccination of adolescents through school programs, in addition to screening in pregnancy. At-risk infants could also be vaccinated against HIV.

Rapid testing, a second technological option in the reduction of MTCT of HIV, is closer to reality. In the case of a high-risk woman who arrives at the hospital in labour and who has not been screened, the goal is to have an HIV test completed within 1 hour of the blood arriving at the laboratory. Currently, the total testing time is affected by 2 factors: (1) the transit time to the public health laboratory, an issue for rural and remote communities in Canada, and (2) the time of day (although after working hours the technicians will return to the laboratory for test results required urgently). What is required, therefore, is a rapid, accurate test that can be done at individual hospitals, so that delay in starting antiretrovirals is minimized and so that treatment decisions for infected women can be quickly put into place. Rapid tests have been used in point-of-contact testing sites in Canada, but have suffered from inaccurary. ${ }^{26}$ The "Oraquick Rapid HIV-1 Antibody Test," approved by the Food and Drug Administration (FDA) for use in the United States on November 7, $2002,{ }^{27}$ has a $99.6 \%$ accuracy, and provides the results in 20 minutes. Such technology will be invaluable in labour wards, when decisions need to be made expeditiously about the individual management of pregnant women, as untreated women with HIV will require antiretroviral drugs for the protection of themselves and their infants. The earlier that their HIV status is known, the sooner that appropriate treatment can be instituted.

There are already preliminary indications that the rapid test is helpful in this setting. In the MIRIAD (Mother-Infant Rapid Intervention at Delivery) Study of the Centers for Disease Control and Prevention (CDC), initiated in November 2001, women who did not know their HIV status at time of late pregnancy or delivery were given the Oraquick test, and offered antiretroviral treatment if found to be HIV-positive. ${ }^{28}$ The results of the rapid test were confirmed by the traditional enzyme immunoassay and, if possible, the Western Blot test, as soon as they were available. Of the 1771 pregnant women tested from November 19, 2001, to November 1, 2002, 12 were detected as HIV-positive. There were no false positive or false negative results. With the recent FDA approval of this rapid testing device, even more women will have the opportunity to accept treatment to prevent their infants from developing HIV, when earlier prenatal testing has not been an option. In the Canadian situation, this would apply in particular to recent immigrants or visitors, and to women who have had no prenatal care. Health Canada would be wise to expeditiously evaluate the use of a rapid testing device for labour wards.

There are many strategies to improve screening rates for HIV in Canada with the goal of reducing MTCT of HIV to $1 \%$, or to transmission caused by the failure of treatment, rather than the failure of diagnosis. The 5 effective risk management strategies are visually represented in Figure 2.

\section{CANADIAN RESPONSIBILITY TO WOMEN IN DEVELOPING COUNTRIES}

There are about 36.1 million people in the world living with HIV/AIDS, of which $47 \%$ are women 15 years of age or older. An estimated 5.1 million children have been infected since the beginning of the epidemic, primarily through $\mathrm{MTCT} .{ }^{29}$ Cana$\mathrm{da}$, as one of the most prosperous nations in the world, has a responsibility not only to reduce MTCT of HIV in Canada, but to help developing nations achieve this goal as well. Any strategies being used or developed to manage MTCT in Canada should be made available to resource-poor countries, where appropriate. In the spirit of this objective, the Canadian International Development Agency (CIDA) has made fighting AIDS an important part of its mandate. ${ }^{30}$ Prevention strategies should always be a priority, and, as in Canada, should focus on the many advisory options available, in particular, education of the public about safe sex and the risks of dirty needles. The training of health-care workers and a move to community action remain essential, and linking communities across continents may help to strengthen advisory strategies. Research for an effective vaccine should include an emphasis on those strains of HIV prevalent in the developing world.

As with any successful risk-management strategy, evaluation is a key component. Ongoing surveillance of the HIV epidemic globally should include a focus on MTCT. Strategic programs in Canada and elsewhere must be evaluated for effectiveness. Most importantly, there needs to be a political will to see the MTCT of HIV as a preventable tragedy, and to act on it. 


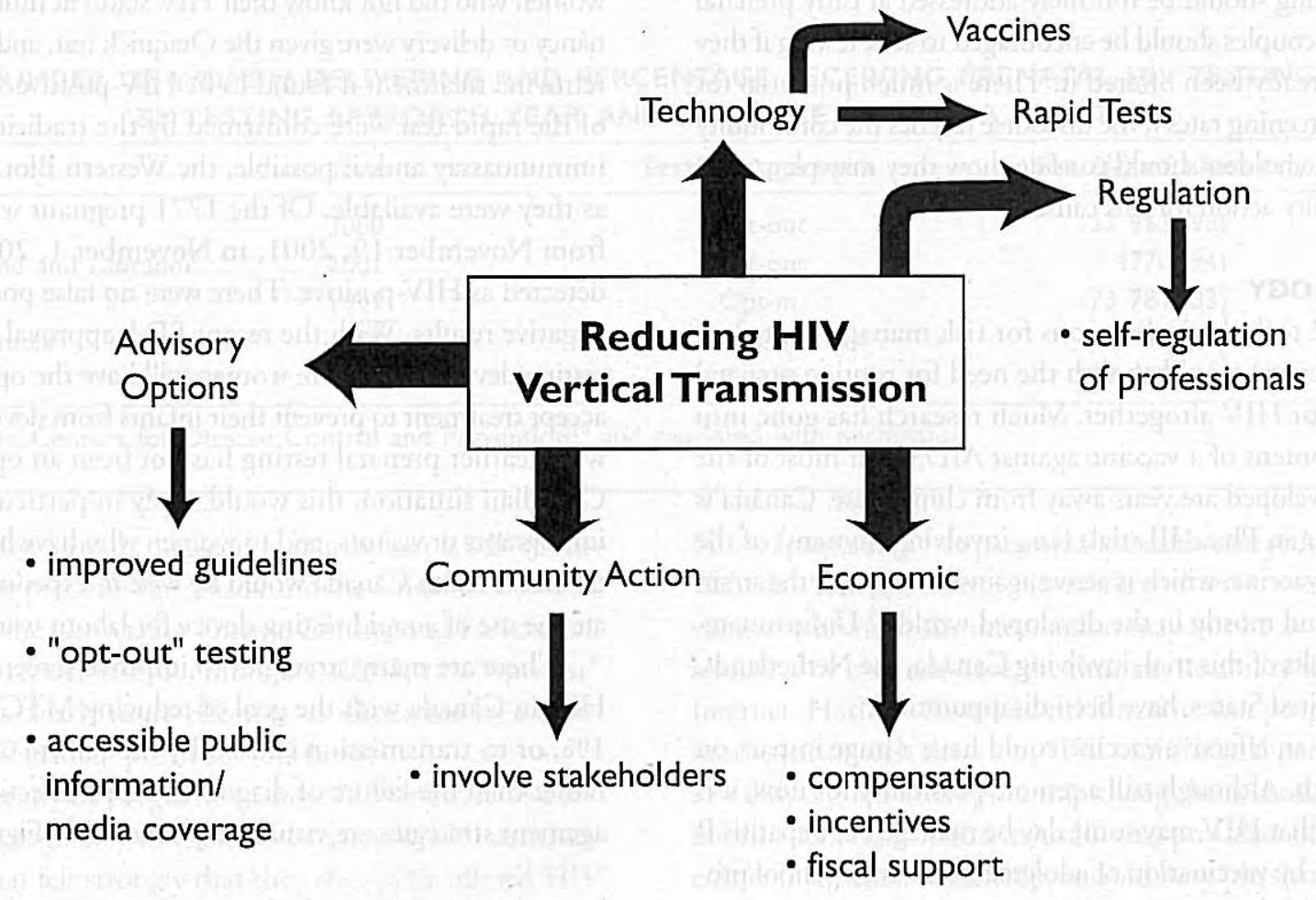

Figure 2. Summary of risk management strategies.

\section{CONCLUSIONS}

It is unacceptable that infants in Canada continue to be born with $\mathrm{HIV}$, as almost all cases of MTCT-acquired HIV infection can be prevented by universal screening of pregnant women, and appropriate treatment. The time is ripe for updating counselling guidelines. "Opt-out" testing has been proven effective at achieving high screening rates, and should be adopted across the country. Provincial laboratory requisitions need to be redesigned so that HIV testing is included in the routine blood work unless the health-care provider specifically indicates that the woman has refused testing.

The World Health Organization mandate "Health for All" applies here, just as it applies elsewhere in the world. Our goal is the health of mothers and fathers, at-risk family members, and the most vulnerable members of our society, our children.

\section{ACKNOWLEDGEMENTS}

The author thanks Dr Andrée Gruslin, for her assistance with references and comments on drafts, and Dr Daniel Krewski, for introducing the author to the subject of population health risk-assessment.

\section{REFERENCES}

I. Centre for Infectious Disease Prevention and Control, Health Canada. HIVIAIDS Epi Update, April 2002. Ottawa: Health Canada; 2002.
2. Fernandez AD, McNeeley DF. Management of the infant born to a mother infected with human immunodeficiency virus type I (HIV-I): current concepts. Am J Perinatol 2000;17(8): 429-36.

3. loannidis JP, Abrams EJ, Ammann A, Bulterys M, Goedert J], Gray L, et al. Perinatal transmission of human immunodeficiency virus type $I$ by pregnant women with RNA virus loads of $<1000$ copies $/ \mathrm{mL}$. $J$ Infect Dis 2001;183:539-45.

4. Remis RS, Guenter D, King S. Testing pregnant women in Canada for HIV: how are we doing? Can Family Phys 2001;47:2193-5.

5. ExpertWorking Group on HIV Testing. Counselling guidelines for HIV testing. Ottawa: Canadian Medical Association; 1995.

6. Maternal-Fetal Medicine Committee. Society of Obstetricians and Gynaecologists of Canada. HIV testing in pregnancy. SOGC Clinical Practice Guidelines, Policy Statement No. 62; June 1997. Available at $<$ http://www.sogc.org/SOGCnet/sogc_docs/common/guide/pdfs/ps62. pdf>. Accessed June 5, 2003.

7. Infectious Diseases and Immunization Committee. Testing for human immunodeficiency virus type I (HIV-I) infection in pregnancy. Canadian Paediatric Society (CPS). Paediatr Child Health 2001;6(9):685-9.

8. Tobin MA, Chow FJ, Bowmer MI, Bally GA. A comprehensive guide for the care of persons with HIV disease, module 2: infants, children and youth. Mississauga: College of Family Physicians of Canada; 1995.

9. MacDonald SR, Skor A, Socol ML, Garcia PM. Human immunodeficiency virus infection and women: a survey of missed opportunities for testing and diagnosis. Am J Obstet Gynecol 1998; 178(6):|264-7|.

10. Gruslin A, Salvador A, Dekker M, Menard-de Varennes D, Eason E. Prenatal HIV screening in a tertiary care centre. Can J Public Health 2001;92(4):255-8.

II. Bitnun A, King SM, Arneson C, Read SE. Failure to prevent perinatal HIV infection. Can Med Assoc J 2002;166(7):904-5.

12. MacDonald SE, O'Connor KS, Hartling L, Seguin R, Masse R, Rekart ML, et al. National survey of practices and attitudes of Canadian physicians towards HIV screening of pregnant women. In: Perinatal HIV transmission: study results and implications for policy and program development. Ottawa: Health Canada; 200I.p. 3-2I. 
13. Parra EO, Doran TI, Ivy LM, Aranda JM, Hernandex C. Concern of pregnant women about being tested for HIV: a study in a predominately Mexican-American population. AIDS Patient Care STDs 200I; I5(2):83-93.

14. SOGC Ethics Committee. Involuntary intervention in the lives of pregnant women.J Soc Obstet Gynaecol Can 1997;19:1200-3.

15. Stoltz L. HIV testing and pregnancy: medical and legal parameters of the policy debate. In: Perinatal HIV transmission: study results and implications for policy and program development. Ottawa: Health Canada; 2001.p. 35-58.

16. HIV and HIV treatment in pregnancy resources page, available through a link on the MotheriskWeb site. Available at <www.motherisk.org>. Accessed July 15, 2003.

17. Leiss W, Krewski D. Risk communication: theory and practice. In: Prospects in risk communication. Waterloo (ON): University of Waterloo Press; 1989. p. 89-1 I2.

18. Remis RS, Patrick DM. Access to prenatal HIV testing. Can Med Assoc J 1998;158(I I):1469-70.

19. Guiding principles for human immunodeficiency virus (HIV) testing of women during pregnancy - 2002. Ottawa: Health Canada; Canada Communicable Disease Report; July 2002;(28-13):I.

20. Centers for Disease Control and Prevention. HIV testing among pregnant women - United States and Canada, 1998-2001. MMWR Morb Mortal Wkly Rep 2002;5I (45):1013-6.

21. Leonard L, Shap L, Pelude L, Hot S. Pregnant women's experiences of screening for HIV in pregnancy: what they have to say about what constitutes an appropriate policy for HIV testing of pregnant women in Canada. In: Perinatal HIV transmission: study results and implications for policy and program development. Ottawa: Health Canada; 2001. p. 23-34.
22. O'Connor KS, MacDonald SE. Aiming for zero: preventing motherto-child transmission of HIV. Can Med Assoc J 2002;166(7):909-10.

23. Walmsley S. Opt in or opt out: what is optimal for prenatal screening for HIV infections? Can Med Assoc J 2003;168(6):707-8.

24. Important news for pregnant women [pamphlet]. Available in English, French, Chinese, Somali, Spanish, Inuktitut, and Swampy Cree. Canadian Public Health Association. Canadian HIV/AIDS Clearinghouse. Ottawa: Canadian Public Health Association; 1997, 1998. Information available on-line at <http://hiv.andornot.com/english/bookbag/default.asp>. Accessed August 3, 2003.

25. Fox M. Against the odds, firm works on AIDS vaccine. Reuters News Service; November 16,2002. Accessed at <www.ABCNews.com>.

26. eCMAJ.Accessed at $<w w w . c m a . c a / c m a j / F D A-A d v i s o r y / h i v-t e s t-$ kit.htm>.

27. FDA News. Accessed at <www.fda.gov/bbs/topics/NEWS/ 2002/NEW00852.html>.

28. Centers for Disease Control, Divisions of HIVIAIDS Prevention. Accessed at <www.cde/gov/hiv/pubs/rt-women.hen\#miriad>

29. Interagency Coalition on AIDS and Development. HIV/AIDS: mother-to-child transmission [newsletter]. Ottawa:The Coalition; August 2001.

30. CIDA takes action against HIVIAIDS around the world. Hull (QC): Canadian International Development Agency; June 2002.

\section{Prevention of Rh Alloimmunization}

This issue of the JOGC includes a

Self-Directed Learning Module on

Prevention of Rh Alloimmunization.

This module qualifies for credits under Section 2 of the

Maintenance of Certification Program

of the Royal College of Physicians and

* Surgeons of Canada.

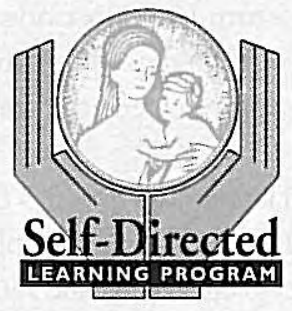

Don't miss this valuable self-directed learning module on Prevention of Rh Alloimmunization.

Supported by an unrestricted educational grant from

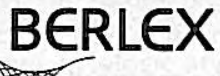

making medicine work

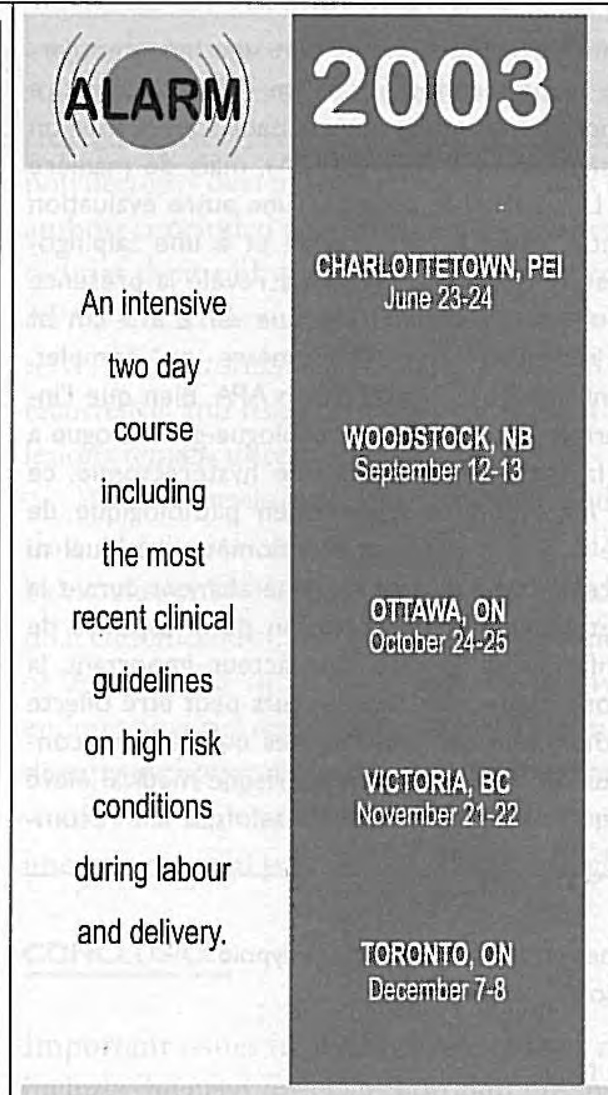

$(6 E S) A))$
II s'agit d'une

session intensive

de deux jours

pendant laquelle

on aborde les plus

récentes directives

cliniques traitant

de situations

à risque élevé

durant le travail et

l'accouchement.

The SOGC gratefully acknowledges the financial support of / La SOGC désire souligner l'appui financier de : Duchesnay Inc., Ferring Pharmaceuticals, Wyeth Pharmaceuticals 